\title{
Genetic variation in agamosporous fern Pteris cretica L. in Japan
}

\author{
Takeshi Suzuki and \\ Kunio Iwatsuki
}

Botanical Gardens, Faculty of Science, University of Tokyo, 3-7-1 Hakusan, Bunkyo-ku, Tokyo 112, Japan.

The genetic variation of an agamosporous fern, Pteris cretica L., was examined by enzyme electrophoresis. Five diploid and six triploid clones were distinguished by differences at five polymorphic enzyme loci. Among the triploids, four clones were characterized by two alleles, $\boldsymbol{H k}^{\mathrm{d}}$ and $\boldsymbol{P g i - 2 ^ { \mathrm { a } }}$, which were not found in either the $2 x$ clones or the two other $3 x$ clones.

These two alleles, $\boldsymbol{H}^{\mathrm{d}}$ and $\boldsymbol{P g i}-\mathbf{2}^{\mathrm{a}}$ were also found in diploid sexual relative of $\boldsymbol{P}$. cretica, $\boldsymbol{P}$. kidoi. This evidence suggests that the $3 x$ clones with these alleles originated through fertilisation of reduced eggs of $P$. kidoi by unreduced spermatozoids of $2 x$ clones $P$. cretica and three different $2 x$ clones of $P$. cretica appear to have participated in crosses with $\boldsymbol{P}$. kidoi to produce $3 \boldsymbol{x}$ clones. Thus recurrent hybridizations contribute toward generating genetic variation among agamosporous species, $P$. cretica.

\section{INTRODUCTION}

Agamospory is one type of asexual reproduction in ferns. Walker (1979) estimated ca. 10 per cent of all the leptosporangiate ferns as agamosporous. In agamosporous ferns, sporophytes produce unreduced spores with same chromosome number as mother sporophytes. Two type of agamospory have been known (Walker, 1979). In predominant type (Döpp-Manton type), spore initial cells make eight spore mother cells through three-time mitosis. Next mitosis is imperfect. Chromosome doubling takes place, but anaphase separation of halfchromosomes and cleavage of cytoplasm are omitted. Each eight unreduced spore mother cells perform meiosis exceedingly regularly, every chromosome pairing with its sister half, and 32 unreduced spores are produced (Manton, 1950). Prothallia from unreduced spores rarely form archegonia, but, in some cases, some antheridia. New sporophyte develops directly from cushion of the prothallium (Kanamori, 1972). Most of agamosporous ferns adopt this Döpp-Manton type (Walker, 1979).

Agamosporous progenies are believed to be genetically identical. Gastony and Gottlieb (1985) showed prothallia of agamosporous Pellaea andromedifolia express same allozymes as their mother plants. Such asexual organisms have been expected to have less genetic variation than sexual species (Asker, 1984). In spite of this expectation, some agamosporous ferns are so variable in phenetic characters as to result in taxonomic confusions.

Walker (1962) demonstrated in his cross experiment of Pteris that fertilisation of reduced eggs of sexual diploids by unreduced spermatozoids of agamosporous diploid can produce triploids which thereafter reproduce agamosporously. He proposed that a new agamosporous higher polyploid may be derived from hybridization between sexual races and agamosporous lower polyploids. Gastony and Gottlieb (1985) electrophoretically examined agamosporous $\mathrm{Pel}$ laea andromedifolia and postulated, with their cytological data, that an agamosporous tetraploid is of hybrid origin between a sexual diploid and an agamosporous triploid. However their enzymatic data did not support this hypothesis. They could not find a reasonable triploid agamosporous parent. On the other hand, Watano and Iwatsuki (1988) showed that an agamosporous tetraploid is of hybrid origin between a sexual diploid and one of three agamosporous triploids in Asplenium unilaterale with unambiguous allozymic evidence. Multiple origins are considered to contribute to 
increasing the genetic variation in an asexual species (Parker, 1979; Ellstrand and Roose, 1985). However, Watano and Iwatsuki (1988) could not demonstrate that recurrent hybridizations occurred because they could find only one tetraploid agamosporous clone.

Pteris cretica L. is an agamosporous complex with cytological and morphological variations, in which Döpp-Manton type was observed (Manton, 1950; Nakato, 1975). Diploid and triploid agamosporous races were reported in Japan (Walker, 1962; Mitui, 1965; Nakato, 1975, 1989). Natural hybrids were reported between $P$. cretica and related sexual species (Nakaike, 1984). Such hybridization may contribute to generating the genetic variation of $P$. cretica. This agamosporous complex seems to be good material for testing if recurrent hybrid origins increase the genetic variation.

The purposes of this study were to examine the genetic variation of agamosporous $P$. cretica by enzyme electrophoresis and to elucidate the origins of genetic variation between $P$. cretica clones. Pteris kidoi Kurata is the only diploid sexual species related to $P$. cretica known in Japan. Taking the hybrid origins of agamosporous clones into consideration, $P$. kidoi was also examined electrophoretically.

\section{MATERIALS AND METHODS}

\section{Cytological observation}

Mitotic observations were performed by the acetoorcein squash method. Root tips were kept in $2 \mathrm{mM}$ 8 -hydroxyquinoline at $23^{\circ} \mathrm{C}$ for $3 \mathrm{~h}$. They were fixed in a mixture of ethanol and 45 per cent acetic acid ( $3: 1$ by volume). Root tips were stained by aceto-orcein and squashed. 44 living plants of $P$. cretica from 24 localities and three plants of $P$. kidoi from two localities were examined.

\section{Enzyme electrophoresis}

For enzyme electrophoresis, 335 individuals of $P$. cretica were collected from 51 localities (fig. 1 and table 1). Nine individuals of $P$. kidoi from three localities were also analyzed (table 2 ). Individuals of $P$. cretica and $P$. kidoi examined cytologically, were also included in this analysis.

Leaves $(0 \cdot 2-0 \cdot 3 \mathrm{~g})$ were ground with a mortar and pestle in $0.6-0.9 \mathrm{ml}$ of extraction buffer modified to Watano and Iwatsuki (1988): $0 \cdot 1 \mathrm{M}$ Tris- $\mathrm{HCl}(p \mathrm{H} 8 \cdot 0), 0.5$ per cent sodium ascorbate, 0.5 per cent sodium metabisulphate, 5 per cent
Table 1 Localities of the materials of Pteris cretica. Numbers in parentheses are numbers of individuals used in this study.

TOHOKU

1. Matsushima-machi, Miyagi Pref. (1)

2. Yoshima-machi, Iwaki-shi, Fukushima Pref. (1)

KANTO

3. Azukibata, Kitaibaragi-shi, Ibaragi Pref. (1)

4. Sakurakawa-mura, Ibaragi Pref. (2)

5. Kan'nonyama, Takasaki-shi, Gunma Pref. (1)

6. Kanasana, Kamikawa-mura, Saitama Pref. (11)

7. Oochi, Nagatoro-machi, Saitama Pref. (1)

8. Ootaki, Ootaki-mura, Saitama Pref. (1)

9. Hirose, Kumagaya-shi, Saitama Pref. (1)

10. Mt. Mitake, Oume-shi, Tokyo Pref. (26)

11. Mt. Takao, Hachiouji-shi, Tokyo Pref. (4)

12. Goudai, Kimitsu-shi, Chiba Pref. (4)

13. Honzawa, Amatsu-kominato-machi, Chiba Pref. (5)

14. Kakibara, Kimitsu-shi, Chiba Pref. (4)

15. Kitakamakura, Kamakura-shi, Kanagawa Pref. (1)

16. Komayama, Ooiso-machi, Kanagawa Pref. (3)

17. Ooyama, Isehara-shi, Kanagawa Pref. (6)

CHUBU

18. Inoshishi-en, Yugawara-machi, Shizuoka Pref. (1)

19. Ootsuki-shi, Yamanashi Pref. (1)

20. Yokokawa, Shizuoka-shi, Shizuoka Pref. (9)

21. Ikawa, Motokawane-machi, Shizuoka Pref. (3)

22. Nihon-Rein, Inuyama-shi, Gifu Pref. (1)

KINKI

23. Mt. Fujiwara, Fujiwara-machi, Mie Pref. (3)

24. Akamekyo, Nahari-shi, Mie Pref. (1)

25. Kotsu, Miyama-cho, Mie Pref. (2)

26. Oharano, Owase-shi, Mie Pref (3)

27. Oouda-machi, Nara Pref. (1)

28. Shirakawa, Uji-shi, Kyoto Pref. (13)

29. Susami-cho, Wakayama Pref. (1)

CHUGOKU

30. Matsugami, Tottori-shi, Tottori Pref. (5)

31. Ikura, Niimi-shi, Okayama Pref. (11)

SHIKOKU

32. Mononobe-machi, Kochi Pref. (1)

33. Nishinokawa, Muro-shi, Kochi Pref. (1)

34. Takanawayama, Saijo-shi, Ehime Pref. (5)

35. Yagawa, Yanagidani-machi, Ehime Pref. (5)

KYUSHU

36. Mt. Raizan, Maebaru-machi, Fukuoka Pref. (3)

37. Yobuno, Yobuno-machi, Fukuoka Pref. (1)

38. Mt. Kaware-ichinotake, Kaware-machi, Fukuoka Pref. (149)

39. Beppu-shi, Ooita Pref. (4)

40. Ebigara-yama, Tsukumi-shi, Ooita Pref. (1)

41. Onagara, Honjo-mura, Ooita Pref. (3)

42. Furenshonyudo, Nozu-machi, Ooita Pref. (4)

43. Furendo, Chuo-machi, Kumamoto Pref. (1)

44. Kosa-dake, Kosa-machi, Kumamoto Pref. (4)

45. Shiraiwato, Izumi-mura, Kumamoto Pref. (2)

46. Iwato-shonyudo, Kuma-mura, Kumamoto Pref. (3)

47. Oose, Kuma-mura, Kumamoto Pref. (3)

48. Mizunashi, Yamae-mura, Kumamoto Pref. (2)

49. Mt. Shibi, Miyanojo-machi, Kagoshima Pref. (2)

50. Takeno-kawa, Itsuki-mura, Kumamoto Pref. (2)

51. Shiiba-mura, Miyazaki Pref. (1) 


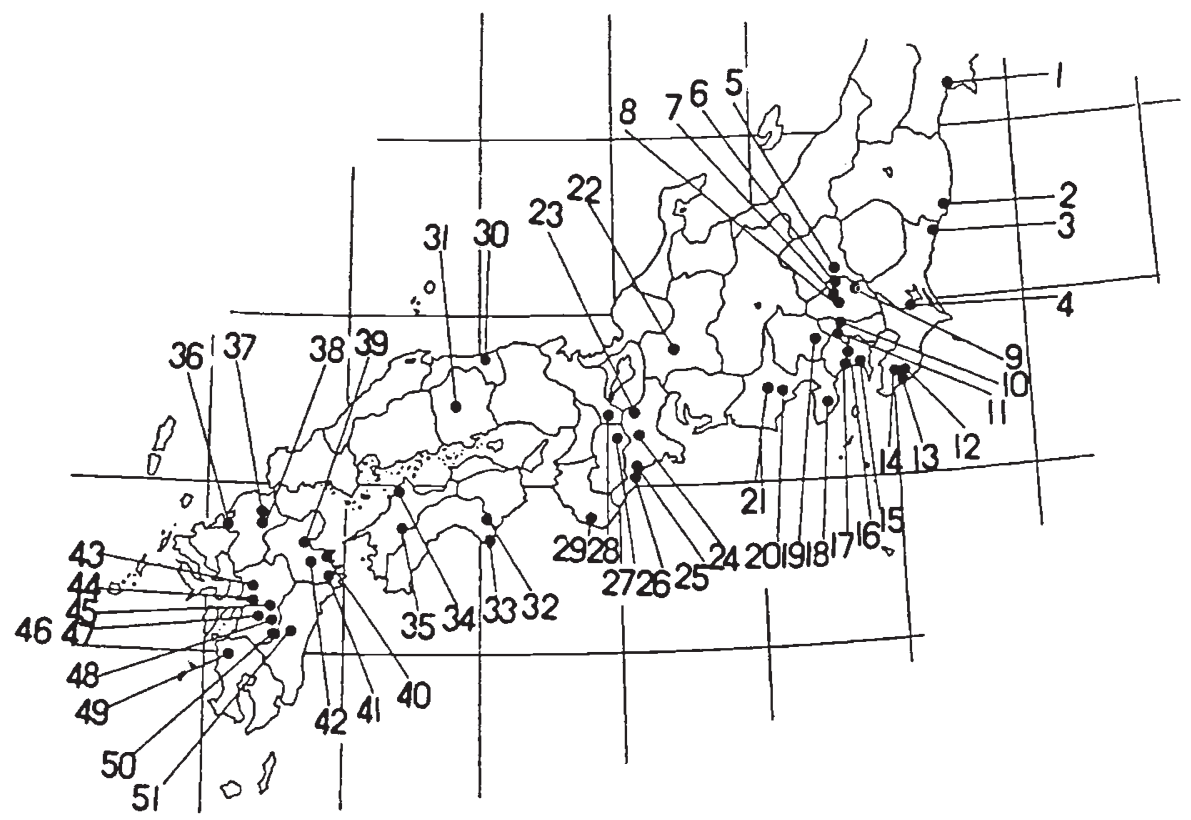

Figure 1 Localities of materials of Pteris cretica L. in this study. See table 1 for locality names.

PVP (Sigma PVP-40T), 0.5 per cent magnesium chloride. $0 \cdot 25$ per cent EDTA disodium salt, $0 \cdot 5$ per cent $(\mathrm{v} / \mathrm{v})$ 2-mercaptoethanol. Crude extracts were centrifuged, and supernatants were used for electrophoresis. In this study, thin-layer horizontal acrylamide gel $(T=5$ per cent, $C=5$ per cent $)$ was used (Watano and Iwatsuki, 1988).

Three buffer systems were employed. Systems I, II, and III were modified from the buffer systems Nos. 8, 7, and 5 of Soltis et al. (1983), respectively. System I was used for aspartate aminotransferase (AAT), hexokinase (HK), leucine aminopeptidase (LAP), phosphoglucoisomerase (PGI), and phosphoglucomutase (PGM). Isocitrate dehydrogenase (IDH) and shikimate dehydrogenase (SKDH) were resolved in system II. For aconitase (ACN), 6-phosphogluconate dehydrogenase (6PGDH), and malate dehydrogenase (MDH), system III was employed. Electrophoresis was performed at $300 \mathrm{~V}$ for $3 \mathrm{~h}$ (system I), at $300 \mathrm{~V}$ for $3.5 \mathrm{~h}$ (system II), and at $100 \mathrm{~V}$ for $8 \mathrm{~h}$ (system III).

The agarose staining schedules of Soltis et al. (1985) were adopted for ACN, HK, IDH, MDH,

Table 2 Localities of the materials of Pteris kidoi. Numbers in parentheses are numbers of individuals used in this study

KYUSHU

Onagara, Honjo-mura, Ooita Pref. (5)

Furen-shonyudo, Nozu-machi, Ooita Pref. (1)

Iwato-shonyudo, Kuma-mura, Kumamoto Pref. (3)
6PGDH, PGI, PGM, and SKDH. Staining schedules for AAT and LAP also followed the method of Soltis et al. (1983).

\section{Estimation of reproduction system}

Spore counting was carried out to determine the reproduction system. Individuals with 32 spores per sporangium were taken to be agamosporous and those with 64 spores sexual (Manton, 1950). For each individual, more than ten sporangia were examined.

\section{RESULTS}

Genetic diversity in agamosporous P. sretica

Of the 44 individuals cytologically examined, 26 individuals were diploid $(2 n=58)$ and the other 18 were triploid $(2 n=87)$. These 44 individuals were examined electrophoretically. Polymorphism was detected for AAT, HK, IDH, LAP, PGI-2, PGM-1, and SKDH, but good resolution could not be obtained in IDH and LAP, which were excluded from further analyses. Individuals showing the same banding pattern for all five enzymes were considered to belong to the same clone. Among 44 individuals, a total of 11 clones were detected by differences in banding pattern for one 


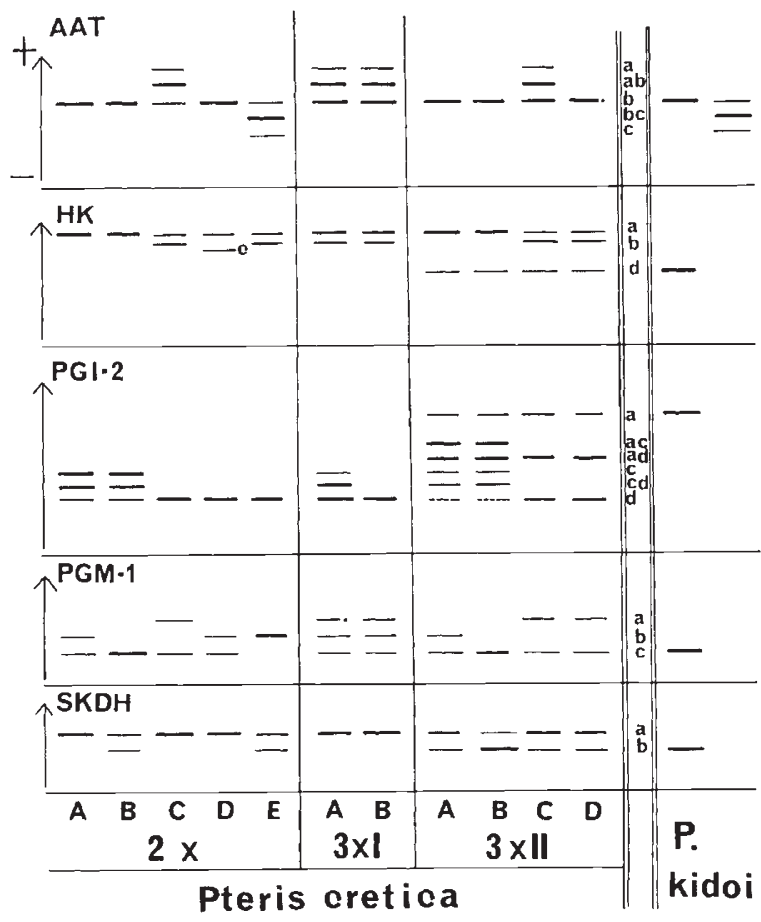

Figure 2 Schematic allozyme banding patterns of eleven clones of $P$. cretica and diploid sexual $P$. kidoi. The anodal side is the upper side of the figure. See text.

or more of these enzymes (fig. 2). Five clones were diploid and the other six were triploid.

The five diploid clones were designated $2 x \mathrm{~A}, \mathrm{~B}, \mathrm{C}, \mathrm{D}$, and E. Of the six triploid clones, four clones had two alleles, $H k^{\mathrm{d}}$ and $P g i-2^{\mathrm{a}}$, which were not found in any of the $2 x$ clones. Based on these data, the $3 x$ clones were divided into two groups; $3 x \mathrm{I}$ group lacks $H k^{\mathrm{d}}$ and $P g i-2^{\mathrm{a}}$ and $3 x \mathrm{II}$ group has them. The $3 x \mathrm{I}$ group contained two clones, $3 x \mathrm{IA}$ and $3 x \mathrm{IB}$, and the $3 x \mathrm{II}$ group included four clones, $3 x$ IIA, B,C, and D.

An additional 291 individuals were examined by enzyme electrophoresis. Each of these 291 individuals showed the same phenotype as one of the eleven clones above.

Spore counting was performed for 55 individuals (more than two individuals for each clone). All individuals examined produced 32 spores in each sporangium. This suggests that all the eleven clones are agamosporous.

Assumed genotypes are listed in table 3. Based on band intensity and ploidy, the genotype of each clone at each locus was inferred. When it was difficult to assume genotypes because of deviation from expected band intensity, phenotypes are recorded as, for example, "a/c". Reduced activity
Table 3 Genotypes (italic) or phenotypes (roman) of eleven clones of Pteris cretica and $P$. kidoi at five polymorphic loci

\begin{tabular}{|c|c|c|c|c|c|}
\hline & Aat & $H k$ & Pgi-2 & Pgm-1 & $S k d h$ \\
\hline \multicolumn{6}{|l|}{ P. cretica } \\
\hline $2 \times \mathrm{A}$ & $b b$ & $a a$ & $c d$ & $b c$ & $a a$ \\
\hline B & $b b$ & $a a$ & $c d$ & $c c$ & $a b$ \\
\hline $\mathrm{C}$ & $a b$ & $a b$ & $d d$ & $a c$ & $a a$ \\
\hline D & $b b$ & $a c$ & $d d$ & $b c$ & $a a$ \\
\hline $\mathrm{E}$ & $b c$ & $a b$ & $d d$ & $b b$ & $a b$ \\
\hline $3 x \mathrm{IA}$ & $a b b$ & $a a b$ & $c d d$ & $a b c$ & $a a a$ \\
\hline B & $a b b$ & $a a b$ & $d d d$ & $a b c$ & $a a a$ \\
\hline $3 x$ II A & $b b b$ & aad & acd & $b / c$ & $a a b$ \\
\hline B & $b b b$ & aad & acd & $c c c$ & $a b b$ \\
\hline $\mathrm{C}$ & $a b b$ & $a b d$ & add & $a / c$ & $a a b$ \\
\hline $\mathrm{D}$ & $b b b$ & $a b d$ & add & $a / c$ & $a a b$ \\
\hline \multicolumn{6}{|l|}{ P. kidoi } \\
\hline & $\begin{array}{l}b b \text { or } \\
b c\end{array}$ & $d d$ & $a a$ & $c c$ & $b b$ \\
\hline
\end{tabular}

of the $d$ subunit at PGI-2 could explain the deviation of band intensities at PGI-2. Genotypes at Pgi-2 are interpreted based on the above assumption.

Geographical distributions of clones are presented in fig. 3 ( $2 x$ clones) and fig. 4 ( $3 x \mathrm{I}$ and $3 x \mathrm{II}$ clones including $P$. kidoi). $2 x \mathrm{~A}$ and $2 x \mathrm{C}$ are widely distributed in Japan, while $2 x \mathrm{~B}, \mathrm{D}$, and $\mathrm{E}$ are restricted to a few localities. $3 x \mathrm{IA}$ is widely distributed, but $3 x \mathrm{IB}$ was found only in two localities. $3 x$ II clones were found in several localities, limited to southwest Japan.

\section{Cytological and electrophoretic analyses of P. kidoi}

Chromosome counts were made for $P$. kidoi $(2 n=$ $58,2 x)$, and were in accordance with the previous report of Nakato (1988). Sporangia of $P$. kidoi were 64-spored, suggesting that this species is sexual.

Zymograms of $P$. kidoi are also shown in fig. 2 , and phenotypes of $P$. kidoi are included in table 3. Intraspecific polymorphism was detected at AAT. All alleles of $P$. kidoi were detected in $P$. cretica. The alleles $H k^{\mathrm{d}}$ and $P g i-2^{\mathrm{a}}$, presented only in $3 x$ II clones of $P$. cretica, were also found in $P$. kidoi.

\section{DISCUSSION}

This study demonstrates that $P$. cretica in Japan includes five diploid and six triploid agamosporous clones. Recurrent origins from sexual diploids is 


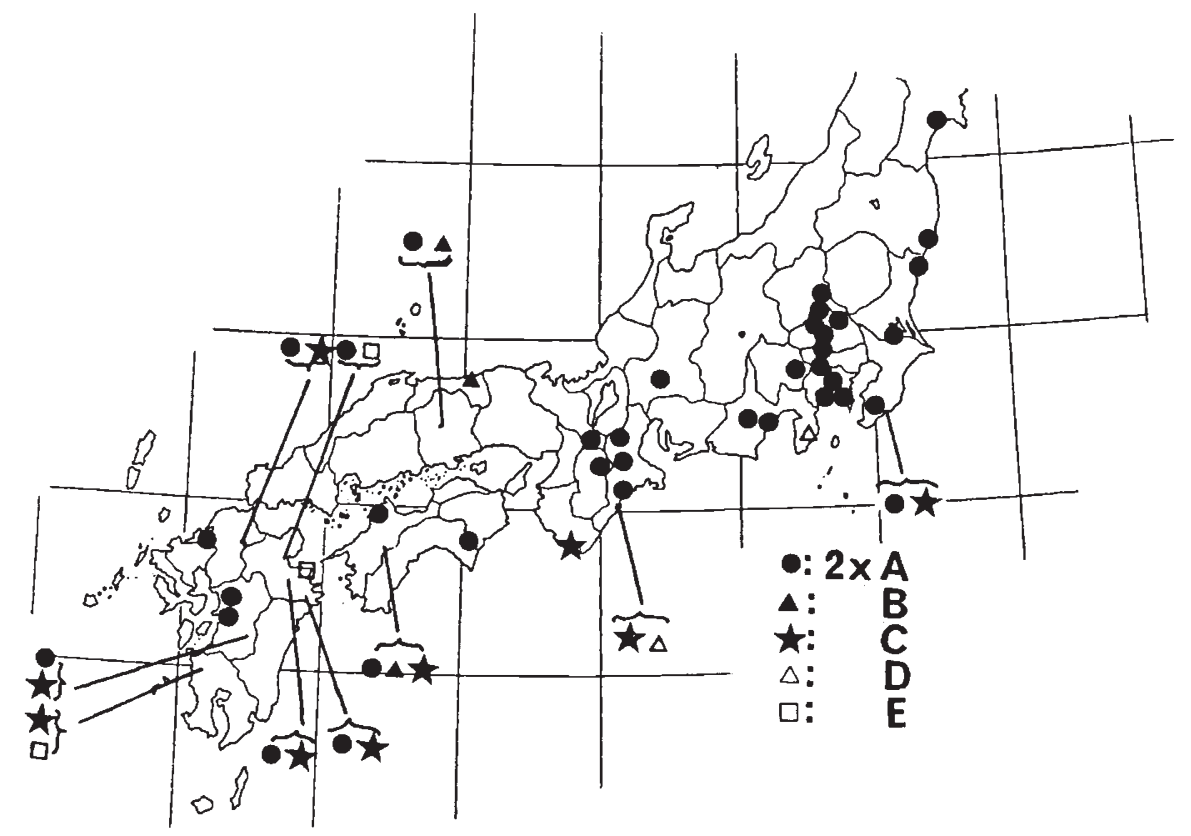

Figure 3 Distribution of $2 x$ clones.

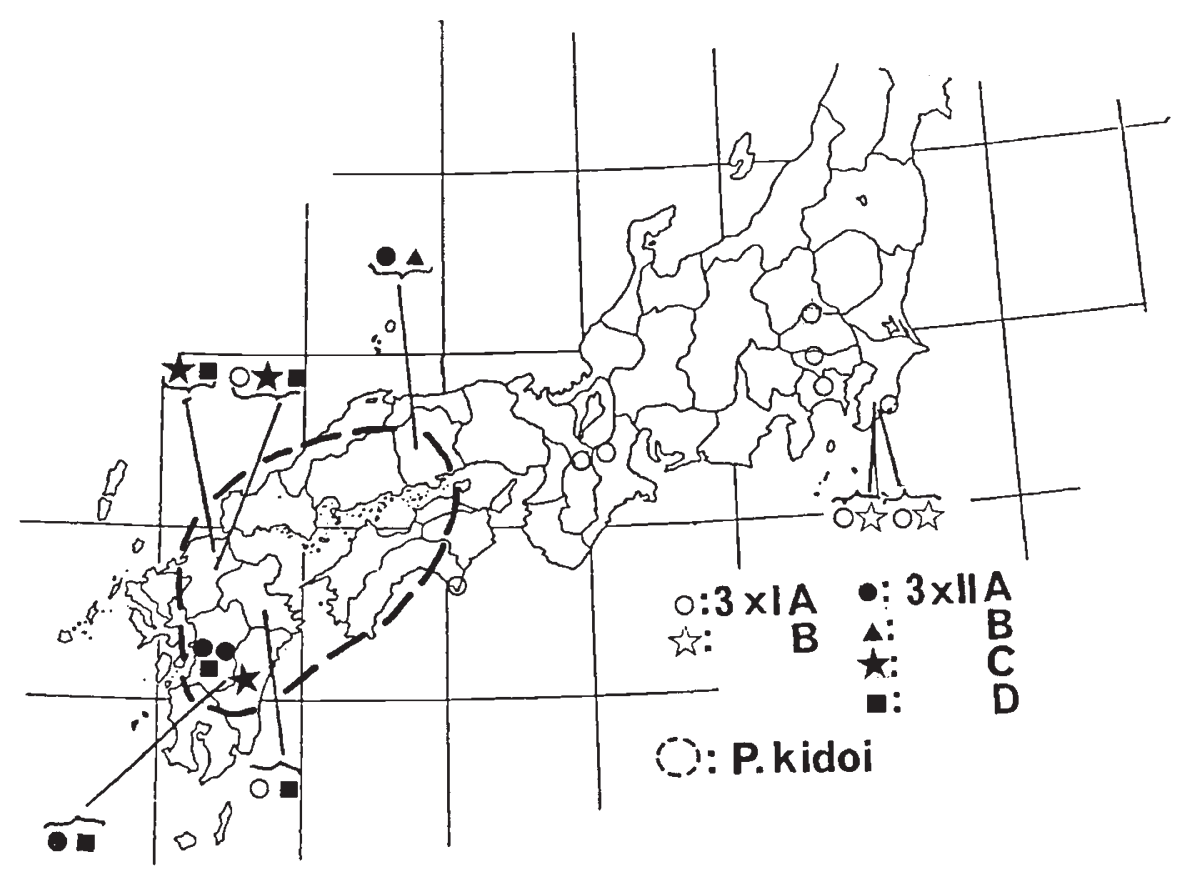

Figure 4 Distribution of $3 x \mathrm{I}$ and $3 x$ II clones of $P$. cretica and $P$. kidoi. Distribution of $P$. kidoi is drawn from Kurata and Nakaike (1979) and Hyodo (personal communication). 
a likely hypothesis for the genetic variation among $2 x$ clones. Although sexual diploids were reported from Indonesia (Walker 1962), these materials were not available in this study. The origins of $2 x$ clones are not discussed in this paper. It is hoped that there will be further work done on the diploid sexual race of $P$. cretica.

\section{Origin of $3 \times 1$ clones}

All alleles detected in the two $3 x$ I clones were also found in the $2 x$ clones of $P$. cretica. There is no evidence that genomes other than those of diploid. $P$. cretica clones are included in $3 x \mathrm{I}$ clones. Gastony (1988) indicated the autopolyploid origins of agamosporous tetraploids in Pellaea glabella complex. As in the case of Pellaea, the $3 x$ I clones in this study may also be of autopolyploid origin.

$P g m-1^{a}$ was detected in both $3 x I$ clones and only in the $2 x \mathrm{C}$ clone among the six $2 x$ clones. This may suggest that both $3 x \mathrm{I}$ clones contain a genome identical to that of the $2 x \mathrm{C}$.

\section{Recurrent hybrid origin of $3 x / 1$ clones between} agamosporous $2 \mathrm{x}$ clones and diploid sexual

\section{P. kidoi}

Two alleles, $H k^{\mathrm{d}}$ and $P g i-2^{\mathrm{a}}$, found in the four $3 x$ II clones were not detected in the $2 x$ clones, but were shared by the related sexual diploid $P$. kidoi. Moreover all alleles in the $3 x$ II clones were detected in either the $2 x$ clones of $P$. cretica or $P$. kidoi. Thus it is indicated that $3 x$ II clones originate through hybridization involving $2 x$ clones and $P$. kidoi.

The geographical distribution of $P$. kidoi overlaps $2 x$ clones in southwest Japan, so $P$. kidoi can hybridize with $2 x$ clones in this area. It is pointed out that $3 x$ II clones were found only in southwest Japan (fig. 4). This evidence supports the above hypothesis.

It is suggested that some agamosporous ferns are of hybrid origin through the fertilisation of the reduced eggs of a sexual race by the unreduced spermatozoids of an agamosporous race (Walker, $1962 ; 1979)$. It is very likely that agamosporous $3 x$ II clones originated from fusion of the unreduced spermatozoids of agamosporous $2 x$ clones and the reduced eggs of diploid sexual $P$. kidoi. Momose (1967) observed spermatozoids in agamosporous prothallia of $P$. cretica. The allele dosages at $H k$ and $P g i-2$ of $P$. cretica are also consistent with this hypothesis. Two doses of $H k^{\mathrm{a}}$ and one dose of $H k^{\mathrm{d}}$ are suggested in $3 x$ IIA and B. $3 x$ IIC and D have $H k^{\mathrm{a}}, H k^{\mathrm{b}}$ and $H k^{\mathrm{d}}$ with one dose. $H k^{\mathrm{a}}$ and $H k^{\mathrm{b}}$ were found among $2 x$ clones, while $H k^{\text {d }}$ was detected in $P$. kidoi. A similar situation was also observed at $P g i-2$ locus $\left(P g i-2^{a}\right.$ in $P$. kidoi and $P g i-2^{\mathrm{c}}$ and $P g i-2^{\mathrm{d}}$ in $P$. cretica). This indicates that $3 x$ II clones have two genomes of $P$. cretica $2 x$ clones and one genome of $P$. kidoi.

According to the above hypothesis of the hybrid origin of $3 x$ II clones, allele comparisons lead to the indication that $2 x \mathrm{C}$ is a reasonable male parent for $3 x$ IIC clone. The genotypes or phenotypes of $3 x$ IIC clone are consistent with those of an expected hybrid (in parentheses) between $2 x \mathrm{C}$ clone of $P$. cretica (two doses) and P. kidoi (one dose): $a b b(a b+b)$ at $A a t, a b d(a b+$ d) at $H k, a d d(d d+a)$ at $P g i-2, \mathrm{a} / \mathrm{c}(a c+c)$ at $P g m-1$ and $a a b(a b+b)$ at $S k d h .2 x \mathrm{~A}$ and B are also reasonable male parents for $3 x$ IIA and $\mathrm{B}$, respectively (table 3 ). It suggests that hybridization between $2 x$ clones of $P$. cretica and $P$. kidoi took place at least three times to produce the agamosporous triploid $3 x$ II clones. For the $3 x$ IID clone, no reasonable parental diploid clone was found in this study.

Alternative hypothesis is segregation by homoeologous pairing at meiosis (Klekowski, 1973). It is difficult to explain genotypic differences between $3 x$ II clones only by segregation. For example, when it is supposed that $3 x$ IIB derived from $3 x$ IIA clone by segregation, additional mutation from $S k d h^{\mathrm{a}}$ to $S k d h^{\mathrm{b}}$ is necessary. It is the case for all combinations of two $3 x$ II clones but $3 x \mathrm{IIC}$ and D. So segregation at meiosis seems a less likely hypothesis for origin genetic variation in $3 x$ II group. It is necessary to compare prothallia genotypes with their parent genotypes in order to test if segregation happens. However, it is more plausible that recurrent hybridization contributed toward increasing the genetic variation among $3 x \mathrm{II}$ clones in the agamosporous species, $P$. cretica.

Acknowledgements This study was partly supported by a grant from the Toray Science Foundation, No. 27-2. We are thankful to Dr Y. Watano for his technical assistance in allozymatic analysis. We would also like to thank Dr N. Nakato for helping us in chromosome observation, collecting the materials and showing us some of his unpublished data. Sincere thanks are also due to the members of the Nippon Fernist Club, especially M. Otomasu, S. Tsutsui and M. Hyodo, for their kind help in the field. We thank Drs D. E. Soltis and P. S. Soltis for their helpful comments on the manuscript. We are also grateful for all of the constructive suggestions given by the members of the Botanical Gardens, University of Tokyo. 


\section{REFERENCES}

ASKER, S. 1984. Apomixis and biosystematics. In Grant, W. F. (ed) Plant Biosystematics. Academic Press, London.

ELlStRAND, N. C. AND ROOSE, M. L. 1987. Patterns of genotypic diversity in clonal plant species. Am. J. Bot., 74, 123-131.

GAstony, G. J. 1988. The Pellaea glabella complex: electrophoretic evidence for the derivations of the agamosporous taxa and a revised taxonomy. Am. Fern J., 78, 44-67.

GASTONY, G. J. AND GOTTLIEB, L. D. 1985. Genetic variation in the homosporous fern Pellaea andromedifolia. Am. J. Bot., 72, 257-267.

KANAMORI, K. 1972. Apogamy in ferns with special reference to the apogamous embryogenesis. Sci. Rep. Tokyo Kyoiku Daigaku, B15, 111-131.

KLEKOWSKI, E. J., JR. 1973. Sexual and subsexual systems in the homosporous ferns: a new hypothesis. Am. J. Bot., 60, 535-544.

KURATA, S. AND NAKAIKe, T. 1979. Illustrations of Pteridophytes of Japan, vol. 1. (In Japanese). University of Tokyo Press, Tokyo.

MANTON, r. 1950. Problems of Cytology and Evolution in the Pteridophyta. Cambridge University Press, London.

MOMOSE, S. 1967. Prothallia of the Japanese ferns (Filicales). (In Japanese). University of Tokyo Press, Tokyo.
NAKAIKE, T. New Flora of Japan; Pteridophyta. (In Japanese). Shibundo, Tokyo.

NAKATO, N. 1975. A cytological study on an intermediate form between Pteris multifida and P. cretica. (In Japanese). Jap. J. Bot., 50, 119-125.

NAKATO, N. 1988. Notes on chromosomes of Japanese pteridophytes (2). Jap. J. Bot., 63, 214-218.

NAKATO, N. 1989. Distributions and fronds variations in diploid and triploid cytotypes in Pteris cretica L. in Kanto District (in Japanese). J. Phytogeo. Taxon., 37, 113-119.

PARKER, E. D. JR. 1979. Ecological implications of clonal diversity in parthenogenetic morphospecies. Am. Zool., 19, 753762.

SOLTIS, D. E., HAUFLER, C. H., DARROW, D. C. AND GASTONY, G. J. 1983. A compilation of grinding buffers, gel and electrode buffers and staining schedules. Am. Fern. J., 73, 9-27.

WALKER, T. G. 1962. Cytology and evolution in the fern genus Pteris L. Evolution, 16, 27-43.

WAlKer, T. G. 1979. The cytogenesis in ferns. In Dyer, A. F. (ed.) The Experimental Biology Of Ferns, Academic Press, London.

WATANO, Y. AND IWATSUKI, K. 1988. Genetic variation in the 'Japanese apogamous form' of the fern Asplenium unilaterale Lam. Bot. Mag. Tokyo, 101, 213-222. 